\title{
Validated Reverse-Phase High-Performance Liquid Chromatography for Quantification of Furosemide in Tablets and Nanoparticles
}

\author{
Ibrahima Youm and Bi-Botti Celestin Youan \\ Laboratory of Future Nanomedecines and Theoretical Chronopharmaceutics, Division of Pharmaceutical Sciences, \\ University of Missouri, Kansas City, MO 64110, USA
}

Correspondence should be addressed to Bi-Botti Celestin Youan; youanb@umkc.edu

Received 25 June 2013; Accepted 7 August 2013

Academic Editor: Josep Esteve-Romero

Copyright (C) 2013 I. Youm and B.-B. C. Youan. This is an open access article distributed under the Creative Commons Attribution License, which permits unrestricted use, distribution, and reproduction in any medium, provided the original work is properly cited.

A simple, sensitive, and specific method for furosemide (FUR) analysis by reverse-phase-HPLC was developed using a Spherisorb $\mathrm{C}_{18}$ ODS 2 column. A chromatographic analysis was carried out using a mobile phase consisting of acetonitrile and $10 \mathrm{mM}$ potassium phosphate buffer solution: $70: 30(\mathrm{v} / \mathrm{v})$ at $\mathrm{pH} 3.85$, at a flow rate of $1 \mathrm{~mL} \cdot \mathrm{min}^{-1}$. The UV-detection method was carried out at $233 \mathrm{~nm}$ at room temperature. Validation parameters including limit of detection (LOD), limit of quantitation (LOQ), linearity range, precision, accuracy, robustness, and specificity were investigated. Results indicated that the calibration curve was linear $\left(r^{2}=0.9997\right)$ in the range of 5.2 to $25,000 \mathrm{ng} \cdot \mathrm{mL}^{-1}$, with $\varepsilon$ value equal to $3.74 \times 10^{4} \mathrm{~L} \cdot \mathrm{M}^{-1} \cdot \mathrm{cm}^{-1}$. The LOD and LOQ were found to be 5.2 and $15.8 \mathrm{ng} \cdot \mathrm{mL}^{-1}$, respectively. The developed method was found to be accurate (RSD less than $2 \%$ ), precise, and specific with an intraday and interday RSD range of 1.233-1.509 and 1.615 to $1.963 \%$. The stability of native FUR has also been performed in simulated perilymph and endolymph media (with respective potency in each medium of $99.8 \pm 2.3 \%$ and $96.68 \pm 0.7 \%, n=3$ ) after 6 hours. This method may be routinely used for the quantitative analysis of FUR from nanocarriers, USP tablets and release media related to hearing research

\section{Introduction}

Furosemide, 5-(aminosulfonyl)-4-chloro-2-[(2 furanylmethyl) amino] benzoic acid, (FUR) a loop diuretic has been used in the treatment of congestive heart failure and edema (Figure 1). FUR acts on thick ascending limb of the loop of Henle leading to a loss of sodium, potassium, and chloride that are dispatched in the urine [1]. This results in a decrease in sodium and chloride reabsorption, while increasing the excretion of potassium in the distal renal tubule. The diuretic effect of orally administered FUR appears within 30 minutes to 1 hour and is maximal in the first or second hour [2]. For the treatment of cardiac diseases, its daily dose is 20 $80 \mathrm{mg}$ for adults [3]. For pediatric use this dose is ranged from $1 \mathrm{mg} \cdot \mathrm{kg}^{-1}$ up to a maximum of $40 \mathrm{mg}$ daily neonates [3].

FUR has been reported to be the etiologic agent responsible for the permanent sensorineural hearing loss [4]. Recent work has demonstrated that FUR decreases the active cochlear mechanics in reducing the threshold shift following broadband continuous noise [5]. Thereby, it reduces the mobility of the basilar membrane of the cochlea and decreases the transduction that normally results from the bending of stereocilia on hair cells [6]. Therefore, FUR can be an appropriate drug model to target the inner ear. It can be also a potential approach for an understanding of the molecular mechanism of ototoxic drugs $[7,8]$. The foregoing facts indicate that an extensive use of FUR results in frequent ototoxicity in humans.

In mice, the total average of the inner ear volume is about $9.7 \pm 0.2 \mu \mathrm{L}$ [9]. In guinea pig, the cochlear perilymph volume is reported to be $15.94 \mu \mathrm{L}$ [10]. Among the primate order, humans have significantly higher cochlear labyrinth volumes. The average volume of the inner ear fluid is reported to be $80.2 \mu \mathrm{L}[11,12]$. In addition to the small volume of the cochlear fluid, a small change of the cochlear fluid volume can impact drastically the high sensitivity of the hearing function. 


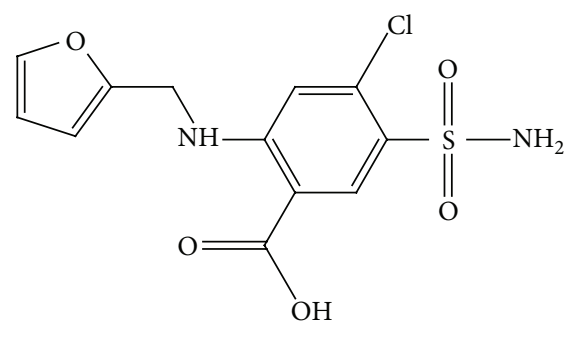

FIGURE 1: Chemical structure of furosemide.

Therefore, the development and validation of an analytical method for FUR determination in biological fluid with a small sampling volume are urgently and critically needed for laboratory scale research.

Several methods including titrimetric, optical and electrochemical detections, and capillary electrophoresis have been used to quantify FUR [13]. Liquid-liquid extraction, followed by solvent evaporation, has been used for sample preparation in the chromatographic analysis of diuretics and probenecid in biological samples. Several reports addressed unresolved issues of precision, time consuming and loss of compounds of interest [14,15]. Other researchers have proposed the use of micellar liquid chromatography for the determination of diuretics, such as FUR in pharmaceutical preparations with an elution time less than $18 \mathrm{~min}$ at a flow rate of $1 \mathrm{~mL} \cdot \mathrm{min}^{-1}[16]$. The literature survey revealed that HPLC has been employed to detect FUR in blood, urine, or perilymph [17-19]. Recently, FUR has been simultaneously determined with spironolactone using HPLC [20]. So far, HPLC is generally the method of choice for diuretics quantitation, due to the required time and cost of the analysis [21].

In this paper, the development and validation of a reproducible RP-HPLC method intended to quantify FUR for routine laboratory use are described, according to the International Conference of Harmonisation (ICH) guidelines [22].

\section{Materials and Methods}

2.1. Chemicals and Reagents. Furosemide, potassium phosphate monobasic $\left(\mathrm{KH}_{2} \mathrm{PO}_{4}\right)$, calcium chloride dehydrate, sodium chloride, potassium chloride, sodium bicarbonate, and potassium bicarbonate were purchased from SigmaAldrich (St. Louis, MO). Furosemide (USP tablets $20 \mathrm{mg}$ ) was provided by Mylan Inc (Canonsburg, PA). Dichloromethane was obtained from ACROS Organics (Morris Plains, NJ). Acetonitrile (HPLC grade) and formic acid were obtained from Fisher Scientific (Pittsburgh, PA). Poly- $\varepsilon$-caprolactonepolyethylene glycol (PCL-PEG, 2k-3k) diblock was supplied by advanced material polymers Inc (Montréal, Canada). Poly (D, L-lactic-co-glycolic acid) $50: 50$ (inherent viscosity, $0.4,0.58$, and $0.8 \mathrm{dL} / \mathrm{g}$ ) were obtained from Birmingham Polymers (Pelham, AL).

2.2. Equipment and Chromatographic Conditions. The liquid chromatographic system included a Waters-1525 Binary
HPLC pump, a Waters 717 Plus autosampler, and a Waters 2487 dual $\lambda$ absorbance detector (Waters Corporation, Milford, MA). The chromatographic analysis of FUR was performed under isocratic elution, using a Spherisorb ODS2 Column, $\mathrm{C}_{18}, 80 \AA, 5 \mu \mathrm{m}, 4.6 \mathrm{~mm} \times 150 \mathrm{~mm}$ (Spherisorb, Queensferry, UK), a mobile phase composed of acetonitrile, and $10 \mathrm{mM}$ potassium phosphate buffer $(\mathrm{pH}=3.85)$ in a ratio $70: 30(\mathrm{v} / \mathrm{v})$. Measurements were performed at $233 \mathrm{~nm}$ at a flow rate $1 \mathrm{~mL} \cdot \mathrm{min}^{-1}$ with an injection volume of 10 microliters. The analyte peak was confirmed by its characteristic retention time of $7.2 \mathrm{~min}$. The mobile phase was degassed by sonication (Model 150 D, VWR, Minneapolis, MN) and filtered through a $0.22 \mu \mathrm{m}$ membrane filter (Whatman, UK). All the above chromatographic parameters were controlled by Waters Breeze software version 3.3 (Waters Corporation, MA).

2.3. Preparation of Stock and Working Standard Solutions. The primary standard solution of FUR was prepared with the mobile phase at a concentration of $25,000 \mathrm{ng} \cdot \mathrm{mL}^{-1}$. The latter solution was further diluted with the mobile phase using a serial dilution method to obtain mixed working standard solutions from 5.2 to $25,000 \mathrm{ng} \cdot \mathrm{mL}^{-1}$.

2.4. Method Validation. The validation method was carried out according to the ICH guidelines [22]. The present work entails evaluation of the following validation characteristics: limit of detection (LOD) and limit of quantitation (LOQ), specificity, linearity, precision, accuracy, recovery, and robustness.

2.4.1. Specificity. The objective of this study was to measure the FUR amount in the occurrence of UV interference in the presence of excipients that may be expected to be present in the nanocarrier (NC) matrix extract. The procedure used to demonstrate the specificity depended on the intended objective of the analytical method. For this purpose, the analyte discrimination was carried out in the presence of the excipients (poly- $\varepsilon$-caprolactone-polyethylene glycol (PCL-PEG) and poly (D, L-lactic-co-glycolic acid) (PLGA)) used for the NC preparation. A small amount of FUR was spiked with appropriate amount of excipients. Three samples of placebo were prepared by dissolving 1,2, and $3 \mathrm{mg}$ of powdered blank NCs in $1.5 \mathrm{~mL}$ of a mixture of acetonitrile/dichloromethane $(14: 1 \mathrm{v} / \mathrm{v})$ for $20 \mathrm{~min}$ at room temperature. Three samples were centrifugated at 15,000 rpm for 15 min (Micro 18R, VWR, Minneapolis, MN). Finally, a volume of $40 \mu \mathrm{L}$ of the supernatant was diluted (7 times). Samples were analyzed by HPLC taking into account the lowest limit of quantification.

2.4.2. Detection Limit and Quantitation Limit. The objective of the determination of the LOD was to establish the minimum level from which an amount of FUR can be reliably detected. The determination of the LOQ aimed to detect the minimum injected amount of drugs that produces quantitative measurements with acceptable precision. The LOD and LOQ were determined using the standard deviation 
of the response and the slope of the calibration curve. The samples were diluted in the mobile phase by serial dilution and analyzed in triplicate. The calibration curve was constructed using drug concentrations (5.2, 62.5, 250, 700, $3,500,14,000$, and $\left.25,000 \mathrm{ng} \cdot \mathrm{mL}^{-1}\right)$. The LOD and LOQ were obtained from (1) and (2) considering Beer-Lambert's law:

$$
\begin{aligned}
& \mathrm{LOD}=\frac{3.3 \sigma}{S}, \\
& \mathrm{LOQ}=\frac{10 \sigma}{S},
\end{aligned}
$$

where $\sigma$ is the standard deviation of the chromatogram peak area containing the analyte in the range of the LOD or the LOQ and $S$ is the slope of the calibration curve [22].

2.4.3. Accuracy and Precision. The purpose of this assay was to verify whether the method will provide the same results in three different concentrations and on three different days.

The precision was determined by repeatability (intraday) and intermediate precision (interday) with standard quality control samples. The accuracy was evaluated by replicating $(n=5)$ the analysis of the samples from three different concentrations of FUR: $5,7.5$, and $10 \mu \mathrm{g} \cdot \mathrm{mL}^{-1} \quad(50,75$, and $100 \%)$. The deviation of the mean from the true value serves as the measure of accuracy and should be less than 15\% [22].

The percent of FUR recovered from a known amount was carried out using data from 5 corresponding responses per day on three consecutive days over the three concentrations listed above. The amount of FUR was estimated by measuring the peak areas and by fitting these values to the straight-line equation of the calibration curve. At each concentration level, the precision should not exceed 15\% [22]. Both accuracy and precision were reported as $\%$ RSD for statistical significance.

2.4.4. Linearity of the Calibration Curve. This study aimed to monitor the relationship between the response (area under curve) and the concentration of FUR. Linearity was evaluated by using seven standard concentrations of FUR ranging between 5.2, 62.5, 250, 700, 3,500, 14,000, and 25,000 ng. $\mathrm{mL}^{-1}$ and analyzed in triplicate. The calibration curve was obtained by plotting the peak area to the spiked theoretical concentrations of FUR from the standard solutions and the regression equations were calculated. Seven samples were quantified using the concentration peak area relationships. The linearity of the calibration curve was evaluated by linear regression analysis. For acceptance, a correlation coefficient $\left(r^{2}\right)$ of 0.99 or better was required [22].

2.4.5. Recovery. The extraction efficiency of FUR was quantified at three different concentrations, 5,000, 7,000 and $9,000 \mathrm{ng} \cdot \mathrm{mL}^{-1}$, as low-, medium-, and high-quality control samples $(50,70$, and $90 \% \mathrm{w} / \mathrm{v}$, resp., $n=3)$. To prepare the sample solution (assay of pharmaceutical preparation), ten tablets (20 mg FUR, USP) were weighed individually to obtain afterwards the average weight. After grinding these tablets with a mortar and a pestle, an equivalent amount of $20 \mathrm{mg}$ of FUR was weighed.
TABLE 1: Experimental design matrix for the robustness study and response values $(n=5)$.

\begin{tabular}{lcccc}
\hline Pattern & $\begin{array}{c}\text { Acetonitrile } \\
\text { percent in } \\
\text { water }(\%) \mathrm{v} / \mathrm{v}\end{array}$ & $\begin{array}{c}\text { Wavelength } \\
(\mathrm{nm})\end{array}$ & $\mathrm{pH}$ & $\begin{array}{c}\text { Flow rate } \\
\left(\mathrm{mL} \cdot \mathrm{min}^{-1}\right)\end{array}$ \\
\hline+--+ & $X_{1}$ & $X_{2}$ & $X_{3}$ & $X_{4}$ \\
++-- & 32 & 228 & 3.7 & 1.1 \\
-++- & 32 & 232 & 3.7 & 0.9 \\
++++ & 28 & 232 & 3.9 & 0.9 \\
-+-+ & 32 & 232 & 3.9 & 1.1 \\
---- & 28 & 232 & 3.7 & 1.1 \\
--++ & 28 & 228 & 3.7 & 0.9 \\
+-+- & 28 & 228 & 3.9 & 1.1 \\
Low & 32 & 228 & 3.9 & 0.9 \\
level & 28 & 228 & 3.7 & 0.9 \\
High & 32 & 232 & 3.9 & 1.1 \\
level & & & &
\end{tabular}

On the other hand, an equivalent amount of FURloaded NCs $(20 \mathrm{mg}$ ) was used in parallel. Both powders were dissolved in a $20 \mathrm{~mL}$ volumetric flask, containing $10 \mathrm{~mL}$ of ethanol, and sonicated for $10 \mathrm{~min}$ to accelerate the dissolution process. The samples were transferred in $2 \mathrm{~mL}$ microcentrifuge tubes (Sigma Aldrich, Saint-Louis, MO) and centrifuged at $15,000 \mathrm{rpm}$ for $15 \mathrm{~min}$. Then, $75 \mu \mathrm{L}$ of each solution was aliquoted in $2 \mathrm{~mL}$ microcentrifuge tubes and diluted in $1.425 \mathrm{~mL}$ of mobile phase to obtain a total volume of $1.5 \mathrm{~mL}$. The extraction recovery of FUR was determined by comparing the obtained chromatogram peak areas with unextracted standards representing $100 \%$ recovery $(n=3)$.

2.4.6. Robustness. The purpose of this test was to demonstrate that the method performance would not be significantly impacted by slight variations of the method parameters. By means of JMP software, version 8 (SAS Institute, Cary, $\mathrm{NC}$ ), a fractional factorial design $\left(2^{k-1}\right)$ was constructed with the aim of calculating the effects of the main chromatographic parameters including acetonitrile/phosphate buffer ratio $\left(X_{1}\right)$, wavelength $\left(X_{2}\right), \mathrm{pH}\left(X_{3}\right)$, and flow rate $\left(X_{4}\right)$ on the chromatogram peak area. A two-level fractional factorial design $\left(2^{4-1}\right)$ was used to evaluate the influence of selected parameters as shown in Table 1. Each experiment was performed in replicate $(n=5)$ and the average was used for computational analysis.

2.5. Determination of the Plate Number. In order to determine the column efficiency, the plate number $(N)$ was calculated using (3)

$$
N=\frac{3000 \times L}{d_{P}},
$$

where $L$ is the column length in centimeter and $d_{P}$ is the packing particle diameter in micrometer. 
2.6. Application Method. This method was applied for the determination of FUR-loaded in polymeric biodegradable NCs and USP tablets. In our previous works, FUR-loaded nanocarriers were successfully synthesized and physicochemically characterized [24]. In this present work, the same method is used to estimate the percent of FUR encapsulation efficiency in nanocarriers.

2.6.1. Determination of the Molar Absorptivity of Furosemide by UV-Spectrometry Method. The $\varepsilon$ value of FUR was calculated by preparing a calibration curve in the concentration range of 1,000-25,000 ng. $\mathrm{mL}^{-1}$, using a UV-Vis spectrophotometer at $233 \mathrm{~nm}$. For each concentration, the absorbance was calculated and a plot was constructed by putting the absorbance on the $y$-axis and the concentration on the $x$-axis. The linear regression data analysis was performed through the experimental points. Setting the intercept of the calibration curve to zero allowed us to obtain the $\varepsilon$ value from the slope of this curve by using the classic Beer-Lambert law:

$$
A=\varepsilon \cdot l \cdot c,
$$

where the absorbance ( $A$ or Abs) of a substance depends on the path length $(l)$, that is, the length of solution through which the light passes. For our cells, $l=1 \mathrm{~cm}$ and the concentration $(c)$ was expressed in moles $\cdot \mathrm{L}^{-1}$ of the substance.

\subsubsection{Determination of the Molar Absorptivity of Furosemide} by HPLC Method. The developed HPLC method was applied for the estimation of the $\varepsilon$ value of FUR. For the calculation of the $\varepsilon$ by HPLC, (4) was rearranged to get the following [25]:

$$
A_{r}=\frac{0.06 \times l \times \varepsilon \mathrm{ng}}{M \times f},
$$

where $A_{r}$ is the area of the drug chromatogram (mAU.s) recorded by the UV detector at $233 \mathrm{~nm}, l$ is the path length (cm), $M$ is the molecular weight of the drug (Dalton), $f$ is the mobile phase flow rate $\left(\mathrm{mL} \cdot \mathrm{min}^{-1}\right)$, and $\mathrm{ng}$ (in nanogram) is the injected drug amount for each injection volume of ten microliters. The elaborated (5) could be used as an alternative tool to better estimate the $\varepsilon$ value of any molecule using HPLC data. In this equation, all other parameters, except $A_{r}$ and $\varepsilon$, were constant for a given drug. Thus, they can be referred to as a constant " $k$ " leading to

$$
A_{r}=\varepsilon \cdot k
$$

In this method, $\varepsilon$ was estimated using the slope of the regression curve generated from the injected amounts and other constants from (5), leading to $k\left(\mathrm{nmol} \cdot \mathrm{Min} \cdot \mathrm{mL}^{-1} \cdot \mathrm{L}^{-1}\right)$ and the corresponding areas $\left(A_{r}\right)$.

2.6.3. Short-Term Stability. This experiment was performed by simulating the cochlear fluid's composition as shown in Table 2 [23]. An accurately weighed quantity of native FUR $(50 \mu \mathrm{g})$ was transferred into $50 \mathrm{~mL}$ of perilymph or endolymph simulated fluid (in accordance with the sink conditions) and incubated in triplicate at $37 \pm 0.2^{\circ} \mathrm{C}$ in
TABLE 2: Chemical composition of the synthetic cochlear fluids without protein (data summary adapted from Wangemann and Schacht) [23].

\begin{tabular}{lcc}
\hline Ion & $\begin{array}{c}\text { Perilymph synthetic media } \\
\text { (Scala vestibuli) }\end{array}$ & $\begin{array}{c}\text { Endolymph synthetic } \\
\text { media }\end{array}$ \\
\hline $\mathrm{Na}^{+}$ & $141 \mathrm{mM}$ & $1.3 \mathrm{mM}$ \\
$\mathrm{K}^{+}$ & $6 \mathrm{mM}$ & $157 \mathrm{mM}$ \\
$\mathrm{Cl}^{-}$ & $121 \mathrm{mM}$ & $132 \mathrm{mM}$ \\
$\mathrm{Ca}^{2+}$ & $0.6 \mathrm{mM}$ & $0.023 \mathrm{mM}$ \\
$\mathrm{CO}^{3-}$ & $18 \mathrm{mM}$ & $31 \mathrm{mM}$ \\
$\mathrm{pH}$ & 7.3 & 7.4 \\
\hline
\end{tabular}

constant stirring for 6 hours. Within this time, samples were taken at each established sampling time (every hour). The withdrawn aliquots $(40 \mu \mathrm{L})$ were diluted with pure water $(7-$ fold) in order to obtain a final concentration in the range of the calibration curve. Then, the resulting samples were analyzed using the above HPLC method.

2.7. Statistical Analysis. A $t$-student test was applied to compare the means of two independent samples. A $P$ value $(P)$ below 0.05 was considered statistically significant. A polynomial equation of the chromatogram area response values was derived from the results of the eight runs in the fractional factorial design.

\section{Results and Discussion}

3.1. Method Development. The aim of this work was to develop a suitable and reproducible new analytical method and routinely determine the amount of FUR. The selection of the chromatographic conditions was based on minimizing the tailing factor, improving the peak symmetry, and reducing the total analysis time. Therefore, a wavelength scanning was first performed in the range of $200-400 \mathrm{~nm}$ using the UV-Vis spectrophotometer. The maximum absorbance of FUR with adequate sensitivity was found to be $233 \mathrm{~nm}$.

To obtain the best ratio of acetonitrile/phosphate buffer $(\mathrm{A} / \mathrm{P})$, experiments were carried out with an $\mathrm{A} / \mathrm{P}$ ratio ranging from 10 to $90 \% \mathrm{v} / \mathrm{v}$. The best $\mathrm{A} / \mathrm{P}$ ratio was found to be $30: 70(\mathrm{v} / \mathrm{v})$. To optimize the mobile phase composition, acetonitrile and $0.01 \mathrm{M}$ potassium phosphate buffer were prepared at different pHs $(3.0,3.5,4.0,5.0$, and 6.0) using formic acid as $\mathrm{pH}$ modifier. At $\mathrm{pH} 3.0$, the peak resolution was found to be low. From pH 4.0 to 6.0, the tailing factor of the FUR peak was poor (1.6 to 1.88).

The best separation of the analyte with high efficiency, peak symmetry, and reproducibility was achieved with a mobile phase composition of A/P; $30: 70$, v/v at pH 3.85. FUR is a rather poorly water-soluble drug (acidic $\mathrm{pKa}=3.22$ ) and contains carboxylic acid group, which is ionized to a great extent $(\mathrm{pH}>\mathrm{pKa})[26,27]$. The relationship between $\mathrm{pKa}$ and $\mathrm{pH}$ and their importance in buffer preparation is known as the classical Henderson-Hasselbalch equation [28, 29].

As indicated, the retention time $(7.2 \mathrm{~min})$ was reproducible (RSD value equal to $0.31 \%$ ) and consistent with 
TABLE 3: Interday and intraday assay reproducibility in aqueous solutions of FUR $(n=5)$.

\begin{tabular}{|c|c|c|c|c|c|c|}
\hline \multirow{2}{*}{$\begin{array}{l}\text { Spiked FUR } \\
\text { concentration } \\
(\mathrm{ng} / \mathrm{mL})\end{array}$} & \multicolumn{3}{|c|}{ Intraday } & \multicolumn{3}{|c|}{ Interday } \\
\hline & $\begin{array}{c}\text { Mean calculated } \\
\text { concentration }(\mu \mathrm{g} / \mathrm{mL})\end{array}$ & $\mathrm{SD}^{*}$ & RSD\% & $\begin{array}{c}\text { Mean calculated } \\
\text { concentration }(\mu \mathrm{g} / \mathrm{mL})\end{array}$ & SD & RSD\% \\
\hline 5,000 & 5.300 & 0.080 & 1.509 & 5.325 & 0.091 & 1.709 \\
\hline 7,500 & 7.464 & 0.092 & 1.233 & 7.429 & 0.120 & 1.615 \\
\hline 10,000 & 10.820 & 0.156 & 1.442 & 10.852 & 0.213 & 1.963 \\
\hline
\end{tabular}

${ }^{*}$ Standard deviation.

published data [30]. In addition, the symmetry factor 1.29 was lower than the upper limit (1.5) according to ICH guidelines and consistent with previous results [31]. From the literature, there is no available data about the plate number of column in FUR quantitation by HPLC. The calculated plate number ( $N$ value using (3)) was found to be 9000 and fulfill the theoretical requirement of the $N$ value $(N \geq 1,000,[32])$.

3.2. Method Validation. The present method was validated according to ICH guidelines [33]. The method validation was performed in terms of specificity, accuracy, precision, LOD, LOQ, recovery, linearity, and robustness.

3.2.1. Specificity. The ability of the method to discriminate the analyte in the presence of the excipients used for the NC preparation was carried out. These excipients included poly$\varepsilon$-caprolactone-polyethylene glycol (PCL-PEG) and poly (D, L-lactic-co-glycolic acid, PLGA). Blank NCs ranged from 106 to $400 \mathrm{~nm}$ in diameter were used to check the specificity of the optimized method. No interfering peak of endogenous compounds around the retention time of FUR was found at $233 \mathrm{~nm}$ (Figure 2(a)). The result showed also an absence of interference of the commercial grade FUR tablets. A well-defined peak at the retention time of FUR was shown, when a known amount of FUR was spiked into the previous colloidal suspension of blank NCs (Figure 2(b)). Therefore, the optimized method is suitable for the detection and quantification of FUR [22].

3.2.2. Detection and Quantitation Limits. The method sensitivity was examined through the determination of the LOD and LOQ using the signal-to-noise approach. LOD was found to be at $5.2 \mathrm{ng} \cdot \mathrm{mL}^{-1}$ corresponding to a concentration of $0.019 \%$ of the working solution $\left(25,000 \mathrm{ng} \cdot \mathrm{mL}^{-1},(1)\right)$. The obtained LOD was lower than those found previously in the literature $[17,34,35]$. The quantitation limit was found to be $15.8 \mathrm{ng} \cdot \mathrm{mL}^{-1}$ (2) corresponding to $0.056 \%$ which is lower than $1 \%$ FUR peak concentration $\left(25,000 \mathrm{ng} \cdot \mathrm{mL}^{-1}\right)$. Both LOD and LOQ fulfill the accepted criteria $(<10 \%)$.

3.2.3. Accuracy and Precision. The accuracy of the analytical method was assessed by comparing a known concentration of FUR to the experimental value. The relative standard deviation (RSD\%) of the intraday precision varied from 1.233 to $1.509 \%$ (Table 3 ), which complies with the acceptance criteria proposed by the ICH guideline (RSD < $2.0 \%)$. However, the precision was evaluated at the above concentration

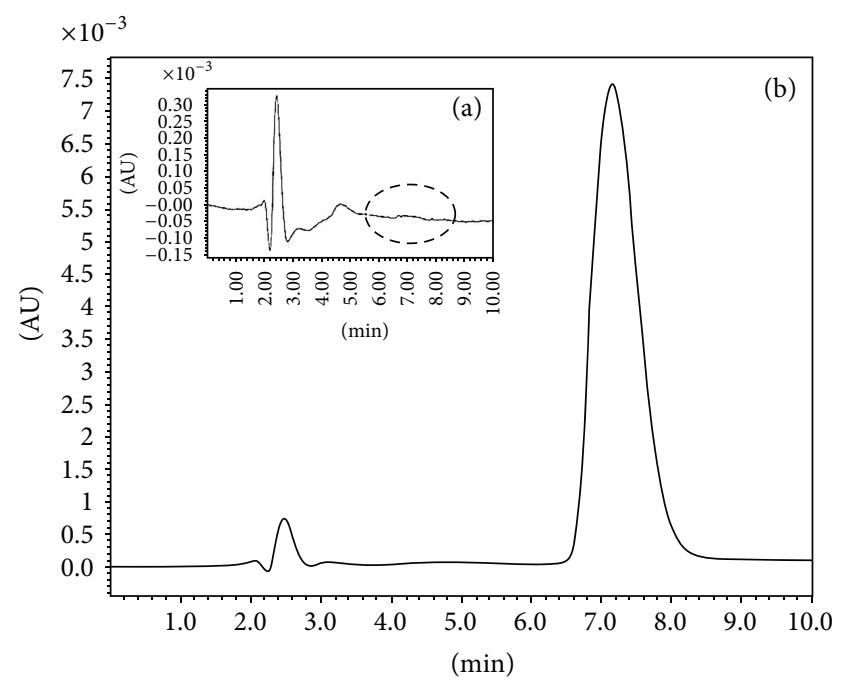

FIGURE 2: Chromatogram of (a) extracts from blank nanocarriers and (b) mixture of $25 \mu \mathrm{g} / \mathrm{mL}$ of FUR (w/vol) with blank nanocarriers.

levels for 3 days with RSD\% between 1.615 and $1.963 \%$. At this concentration range, the upper limit was in the limit of acceptance criteria of ICH guideline [22].

3.2.4. Linearity and Range. The linearity of the relationship between the measured and theoretical drug concentrations was investigated. The measured concentration of FUR was obtained from the linear regression analysis of the calibration curve. A typical calibration curve of FUR peak area within a concentration range of 5.2 to $25,000 \mathrm{ng} \cdot \mathrm{mL}^{-1}$ was obtained with the following linear regression line: $Y=54,061 X-$ $1,769.2\left(r^{2}=0.9997\right)$. The latter equation confirms also that $y$-intercept at zero concentration of FUR was not negligible.

3.2.5. Recovery. FUR from nanocarriers and tablets was quantified at concentrations of 5,7 , and $9 \mu \mathrm{g} / \mathrm{mL}(50,70$, and $90 \% \mathrm{w} / \mathrm{w}$, resp.). These data fulfilled the acceptance ICH criteria (Table $4, \mathrm{RSD}<2 \%$ ) and were consistent with previous study [36].

3.2.6. Robustness. The robustness of a method is an indication of its reliability during the analytical procedure. A fractional factorial design $\left(2^{k-1}\right)$ was constructed with the aim of calculating the effects of a deliberate change of the main chromatographic parameters $\left(X_{i}\right)$ on the chromatogram peak 


\begin{tabular}{|c|c|c|c|c|c|c|c|}
\hline Term & Estimate & Std error & $t$-ratio & & & & Prob $>|t|$ \\
\hline$\overline{X_{1} * X_{3}}$ & -276702.6 & 7291.438 & -37.95 & & & & $0.0168^{*}$ \\
\hline$X_{1}(28 ; 32)$ & -180516.6 & 7291.438 & -24.76 & $\begin{array}{l}1 \\
1 \\
1\end{array}$ & & $\begin{array}{ll}1 & 1 \\
1 & 1\end{array}$ & $0.0257^{*}$ \\
\hline$X_{2}(228 ; 232)$ & 64998.688 & 7291.438 & 8.91 & $\begin{array}{lll}1 & 1 & 1 \\
1 & 1 & 1\end{array}$ & & 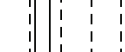 & 0.0711 \\
\hline$X_{4}(0.9 ; 1.1)$ & -29995.81 & 7291.438 & -4.11 & $\begin{array}{lll}1 & 1 & 1 \\
1 & 1 & 1 \\
1 & 1 & 1\end{array}$ & & \begin{tabular}{l|ll}
1 & 1 & 1 \\
1 & 1 & 1
\end{tabular} & 0.1518 \\
\hline$X_{3}(3.7 ; 3.9)$ & 20636.938 & 7291.438 & 2.83 & $\begin{array}{lll}1 & 1 & 1 \\
1 & 1 & 1 \\
1 & 1 & 1\end{array}$ & & \begin{tabular}{l|ll}
1 & 1 & 1 \\
1 & 1 & 1 \\
1 & 1 & 1
\end{tabular} & 0.2162 \\
\hline$X_{1} * X_{2}$ & -2189.563 & 7291.438 & -0.30 & $\begin{array}{lll}1 & 1 & 1 \\
1 & 1 & 1\end{array}$ & 1 & $\begin{array}{lll}1 & 1 & 1 \\
1 & 1 & 1\end{array}$ & 0.8143 \\
\hline
\end{tabular}

FIGURE 3: Pareto chart showing the effects of HPLC parameters on the chromatographic peak area.

TABLE 4: Determination of the percent encapsulation efficiency $(\mathrm{EE} \%, \pm \mathrm{SD})$ in USP tablet and FUR-loaded nanocarriers $(n=3)$.

\begin{tabular}{lccc}
\hline $\begin{array}{l}\text { Percent of theoretical drug } \\
\text { amount (\%) }\end{array}$ & \multicolumn{2}{c}{ FUR-loaded nanocarriers } & \multicolumn{2}{c}{ Furosemide tablet USP } \\
\hline 90 & $90.84 \pm 1.77$ & RSD\% & Recovery \\
70 & $69.32 \pm 0.89$ & 1.95 & $88.26 \pm 1.75$ \\
50 & $49.56 \pm 0.23$ & 1.28 & $68.72 \pm 1.18$ \\
\hline
\end{tabular}

area $(Y) . X_{1}$ represented the percentage of acetonitrile $(\mathrm{v} / \mathrm{v})$ in the mobile phase, $X_{2}$ was the UV wavelength, $X_{3}$ was the $\mathrm{pH}$ of the mobile phase, and $X_{4}$ was taken as the flow rate of the mobile phase. As expected, the chromatogram peak area decreased when the content of acetonitrile was increased from 28 to $32 \%(\mathrm{v} / \mathrm{v})$.

The Pareto chart of the effects of chromatographic parameters on the peak area was shown in Figure 3. A negative sign of the $t$-ratio indicated a negative effect of the chromatographic parameter on the $Y$ value, while a positive sign of the $t$-ratio indicated a positive effect of the chromatographic parameter on the $Y$ value. It was clearly shown that $X_{1}$ and its interaction with $X_{3}$ had a statistically significant negative impact on the $Y$ value $(P=0.0257$ and 0.0168 , resp.). This seemed to indicate that an increase of the volume of acetonitrile in the mobile phase may lead to underestimate the drug quantification. This result can be attributed to a weakness of the buffer strength of the mobile phase when the acetonitrile volume is increased. Indeed, at pHs above the pKa of FUR, the acidic group of the analyte will be negatively charged, thus increasing its polarity. Therefore, an adequate retention would be achieved in adding a small volume aqueous mobile phase, knowing that the retention time of such hydrophobic analyte may also be extended [37, 38].

However, $X_{2}, X_{3}$, and $X_{4}$ had no significant effects on the $Y$ value $(P=0.0711,0.2162$, and 0.1518 , resp.). This appeared to indicate that the method was enough robust at these working conditions. For a better use of the validated method, the percent of acetonitrile and its interaction with the mobile phase $\mathrm{pH}$ should be carefully controlled.

\subsection{Application Method}

3.3.1. Calculation of the Molar Absorptivity ( $\varepsilon$ ). The calibration curves constructed in the concentration ranged defined in Table 6 for the determination of the $\varepsilon$ value using a UVVis spectrophotometer and HPLC were found to be linear with correlation coefficient $\left(r^{2}=0.999\right.$ and 0.996, resp., Table 5). Prior to this application method, a calibration curve was developed for the analysis of FUR.

By applying a UV spectrophotometric procedure, a regression analysis of Beer Lambert's law showed a good correlation in the concentration ranged defined in Table 6 with a molar absorptivity of $3.66 \times 10^{4} 141.27 \pm \mathrm{L} \cdot \mathrm{M}^{-1} \cdot \mathrm{cm}^{-1}$ $(n=3)$.

By applying the HPLC method, the results indicated that the calculated molar absorptivity was $3.74 \times 10^{4} \pm 398.74$ $\mathrm{L} \cdot \mathrm{M}^{-1} \mathrm{~cm}^{-1}(n=3)$, Table 6 . Using the Student $t$-test, the difference between these two values (both from UV spectrophotometry and HPLC) was not statistically significant $(P=0.9975)$ and not consistent with previous report [39].

3.3.2. Stability Test. Preliminary study in the author's laboratory indicated that FUR's solubility increased in simulated endolymph and perilymph media: 500,000 $\mathrm{ng} \cdot \mathrm{mL}^{-1}$ 
TABLE 5: Data from linear standard curves, obtained separately by plotting $Y$ versus $X$.

\begin{tabular}{ccccc}
\hline & Number of points & Range & Correlation coefficient $\left(r^{2}\right)$ & Equation \\
\hline $\mathrm{a}$ & 5 & $0-2 \mathrm{~mol} \cdot \mathrm{L}^{-1}$ & 0.9989 & Abs $=36,501 \cdot \mathrm{C}$ \\
$\mathrm{b}$ & 7 & $0-0.05 \mathrm{nmol} \cdot \mathrm{min} \cdot \mathrm{mL}^{-1} \cdot \mathrm{L}^{-1}$ & 0.9956 & Area $=37,357 \cdot \mathrm{K}$ \\
\hline
\end{tabular}

${ }^{a}$ Absorbance $(Y, \mathrm{AU})$ versus FUR concentration $\left(X, \mathrm{~mol} \cdot \mathrm{L}^{-1}\right)$.

${ }^{\mathrm{b}}$ Area of chromatogram $(Y, \mathrm{mAU} \cdot \mathrm{s})$ versus $K\left(X, \mathrm{nmol} \cdot \mathrm{min} \cdot \mathrm{mL}^{-1} \cdot \mathrm{L}^{-1}\right)$.

TABLE 6: Determination of the molar absorptivity by UV spectrophotometry and HPLC.

\begin{tabular}{|c|c|c|c|c|c|c|}
\hline Method & Calibration range $(\mathrm{ng} / \mathrm{mL})$ & Equation & $r^{2}$ & Slope $(\varepsilon)$ & Mean & Relative standard deviation (\%) \\
\hline \multirow{3}{*}{ UV } & \multirow{3}{*}{$1,000-25,000$} & Abs $=36,745 k$ & 0.996 & 36,745 & & \\
\hline & & $\mathrm{Abs}=36,506 k$ & 0.992 & 36,506 & & \\
\hline & & Abs $=36,495 k$ & 0.998 & 36,495 & 36,582 & 0.386 \\
\hline \multirow{3}{*}{ HPLC } & \multirow{3}{*}{$1,000-25,000$} & Area $=37,023 c$ & 0.998 & 37,023 & & \\
\hline & & Area $=37,819 c$ & 0.995 & 37,819 & & \\
\hline & & Area $=37,379 c$ & 0.993 & 37,379 & 37,407 & 1.065 \\
\hline
\end{tabular}

and $41,000 \mathrm{ng} \cdot \mathrm{mL}^{-1}$, respectively versus $6,000 \mathrm{ng} \cdot \mathrm{mL}^{-1}$ in water (unpublished data). Indeed, the increased $\mathrm{pH}$ value of the medium improved the solubility of FUR. Also the degree of ionization may be responsible for the increase in solubility in the cochlea simulated media. The obtained results (from simulated perilymph and endolymph) showed that FUR $(50 \mu \mathrm{g})$ was stable over the course of the experiment (6 hours). The obtained data indicate a minimum decrease of the drug concentration below the minimum percentage (95\%, Figure 4). Bearing in mind the small volume of the cochlear compartment and its sensitivity to small change in volume, the developed HPLC method could be useful by filling this compartment with $40 \mu \mathrm{L}$ simulated perilymph $\left(0.5 \mu \mathrm{L} \cdot \mathrm{min}^{-1}\right)$ after collecting $40 \mu \mathrm{L}$ of perilymph sample.

\section{Conclusion}

The present HPLC method was exhibited acceptable to have sensitivity, linearity, precision, robustness, low limit of detection, and quantitation according to the ICH guideline. Results from the developed method provided satisfactory outcomes with low level of detection, good accuracy, small sampling volume, and low degree of interference of inactive ingredients from NCs and tablets. The method application allowed the determination of the FUR EE\% from the NCs with accurate results. A good estimation of the molar absorptivity and FUR stability in simulated cochlea fluid can be obtained using the validated method. Due to the widespread use of FUR resulting in ototoxicity concerns, an increasing interest in FUR quantitation in inner ear fluids could be expected in the near future.

\section{Acknowledgments}

The authors are grateful to Dr. Cydney E. McQueen, Clinical Associate Professor, Division of Pharmacy Practice (School of Pharmacy, University of Missouri, Kansas City, MO, USA), for kindly assisting in furosemide USP tablets purchase. They also thank Dr. Michael Anne Gratton, Research Assistant

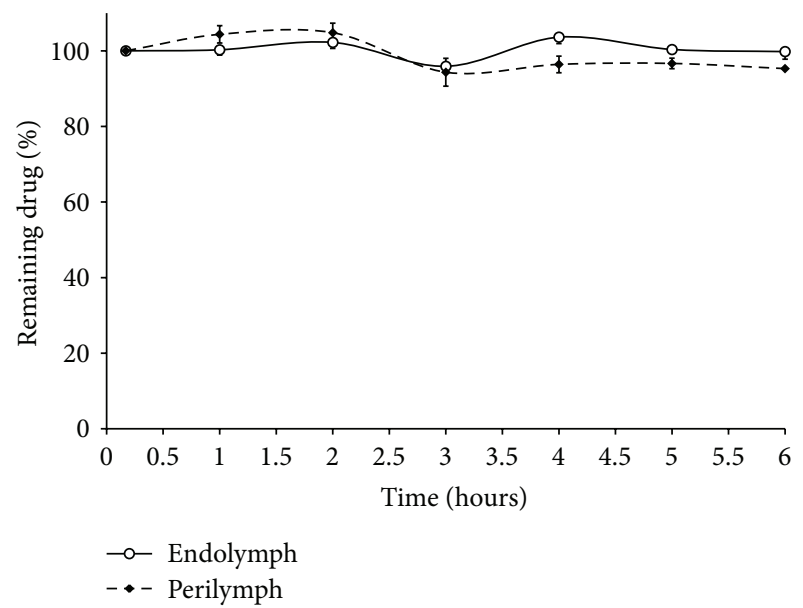

FIGURE 4: Stability of FUR in simulated cochlear fluid $(n=3)$.

Professor (St. Louis University, Department of Otolaryngology, St. Louis, MO, USA), for her helpful discussion at the beginning of this project.

\section{References}

[1] G. Giebisch, "The use of a diuretic agent as a probe to investigate site and mechanism of ion transport processes," ArzneimittelForschung, vol. 35, no. 1, pp. 336-342, 1985.

[2] S. A. Qureshi and I. J. McGilveray, "Assessment of pharmaceutical quality of furosemide tablets from multinational markets," Drug Development and Industrial Pharmacy, vol. 24, no. 11, pp. 995-1005, 1998.

[3] D. P. Patel, C. M. Setty, G. N. Mistry et al., "Development and evaluation of ethyl cellulose-based transdermal films of furosemide for improved in vitro skin permeation," The American Association of Pharmaceutical Scientists PharmSciTech, vol. 10, no. 2, pp. 437-442, 2009.

[4] C. A. Quick and W. Hoppe, "Permanent deafness associated with furosemide administration," Annals of Otology, Rhinology and Laryngology, vol. 84, no. 1, pp. 94-101, 1975. 
[5] C. Adelman, J. M. Weinberger, L. Kriksunov, and H. Sohmer, "Effects of furosemide on the hearing loss induced by impulse noise," Journal of Occupational Medicine and Toxicology, vol. 6, no. 1, article 14, 2011.

[6] M. A. Ruggero and N. C. Rich, "Furosemide alters organ of Corti mechanics: evidence for feedback of outer hair cells upon the basilar membrane," Journal of Neuroscience, vol. 11, no. 4, pp. 1057-1067, 1991.

[7] J. G. Yorgason, J. N. Fayad, and F. Kalinec, "Understanding drug ototoxicity: molecular insights for prevention and clinical management," Expert Opinion on Drug Safety, vol. 5, no. 3, pp. 383-399, 2006.

[8] W. F. Sewell, "The effects of furosemide on the endocochlear potential and auditory-nerve fiber tuning curves in cats," Hearing Research, vol. 14, no. 3, pp. 305-314, 1984.

[9] K. Do, K. Baker, M. Praetorius, and H. Staecker, "A mouse model of implantation trauma," International Congress Series, vol. 1273, pp. 167-170, 2004.

[10] Y. Shinomori, D. S. Spack, D. D. Jones, and R. S. Kimura, "Volumetric and dimensional analysis of the guinea pig inner ear," Annals of Otology, Rhinology and Laryngology, vol. 110, no. 1, pp. 91-98, 2001.

[11] E. E. L. Swan, M. J. Mescher, W. F. Sewell, S. L. Tao, and J. T. Borenstein, "Inner ear drug delivery for auditory applications," Advanced Drug Delivery Reviews, vol. 60, no. 15, pp. 1583-1599, 2008.

[12] M. Thorne, A. N. Salt, J. E. DeMott, M. M. Henson, O. W. Henson Jr., and S. L. Gewalt, "Cochlear fluid space dimensions for six species derived from reconstructions of three-dimensional magnetic resonance images," Laryngoscope, vol. 109, no. 10, pp. 1661-1668, 1999.

[13] M. E. Bosch, A. J. R. Sánchez, F. S. Rojas, and C. B. Ojeda, "Recent developments in analytical determination of furosemide," Journal of Pharmaceutical and Biomedical Analysis, vol. 48, no. 3, pp. 519-532, 2008.

[14] P. Campíns-Falcó, R. Herráez-Hernández, and A. SevillanoCabeza, "Improved detection limits for screening of diuretics by coupled liquid chromatography and ultraviolet-visible spectrophotometry," Journal of Chromatography B, vol. 612, no. 2, pp. 245-251, 1993.

[15] I. Nakurte, A. Keisa, and N. Rostoks, "Development and validation of a reversed-phase liquid chromatography method for the simultaneous determination of indole-3-acetic acid, indole-3-pyruvic acid, and abscisic acid in barley (Hordeum vulgare L.)," Journal of Analytical Methods in Chemistry, vol. 2012, Article ID 103575, 6 pages, 2012.

[16] S. Carda-Broch, J. Esteve-Romero, and M. C. García-AlvarezCoque, "Furosemide assay in pharmaceuticals by micellar liquid chromatography: study of the stability of the drug," Journal of Pharmaceutical and Biomedical Analysis, vol. 23, no. 5, pp. 803-817, 2000.

[17] A. A. Nava-Ocampo, E. Y. Velázquez-Armenta, H. ReyesPérez, E. Ramirez-Lopez, and H. Ponce-Monter, "Simplified method to quantify furosemide in urine by high-performance liquid chromatography and ultraviolet detection," Journal of Chromatography B, vol. 730, no. 1, pp. 49-54, 1999.

[18] Y. S. El-Saharty, "Simultaneous high-performance liquid chromatographic assay of furosemide and propranolol HCL and its application in a pharmacokinetic study," Journal of Pharmaceutical and Biomedical Analysis, vol. 33, no. 4, pp. 699-709, 2003.

[19] H. J. Guchelaar, L. Chandi, O. Schouten, and W. A. van den Brand, "A high performance liquid chromatographic method for the screening of 17 diuretics in human urine," Fresenius' Journal of Analytical Chemistry, vol. 363, no. 7, pp. 700-705, 1999.

[20] V. R. Ram, P. N. Dave, and H. S. Joshi, "Development and validation of a stability-indicating HPLC assay method for simultaneous determination of spironolactone and furosemide in tablet formulation," Journal of Chromatographic Science, vol. 50, no. 8, pp. 721-726, 2012.

[21] D. Q. Chen, J. M. An, Y. L. Feng, T. Tian, X. Y. Qin, and Y. Y. Zhao, "Cloud-point extraction combined with liquid chromatography for the determination of ergosterol, a natural product with diuretic activity, in rat plasma, urine, and faece," Journal of Analytical Methods in Chemistry, vol. 2013, Article ID 479056, 8 pages, 2013.

[22] ICH, "Validation of analytical procedures: methodology, adopted in 1996," in Proceedings of the International Conference On Harmonisation, Geneva, Switzerland, 2005.

[23] P. Wangemann and J. Schacht, "Homeostatic mechanisms in the cochlea," in The Cochlea, P. A. Dallos and R. R. Fay, Eds., pp. 130-185, Springer, New York, NY, USA, 1996.

[24] I. Youm, J. B. Murowchick, and B. B. C. Youan, "Entrapment and release kinetics of furosemide from pegylated nanocarriers," Colloids and Surfaces B, vol. 94, pp. 133-142, 2012.

[25] M. Pelillo, M. E. Cuvelier, B. Biguzzi, T. G. Toschi, C. Berset, and G. Lercker, "Calculation of the molar absorptivity of polyphenols by using liquid chromatography with diode array detection: the case of carnosic acid," Journal of Chromatography A, vol. 1023, no. 2, pp. 225-229, 2004.

[26] M. Efentakis, A. Koutlis, and M. Vlachou, "Development and evaluation of oral multiple-unit and single-unit hydrophilic controlled-release systems," The American Association of Pharmaceutical Scientists PharmSciTech, vol. 1, no. 4, pp. 62-70, 2000.

[27] B. Devarakonda, D. P. Otto, A. Judefeind, R. A. Hill, and M. M. de Villiers, "Effect of $\mathrm{pH}$ on the solubility and release of furosemide from polyamidoamine (PAMAM) dendrimer complexes," International Journal of Pharmaceutics, vol. 345, no. 1-2, pp. 142-153, 2007.

[28] L. J. Henderson, "Concerning the relationship between the strength of acids and their capacity to preserve neutrality," The American Journal of Physiology, vol. 21, no. 4, pp. 173-179, 1908.

[29] K. A. Hasselbalch, "Die Berechnung der Wasserstoffzahl des Blutes aus der freien und gebundenen Kohlensäure desselben, und die Sauerstoffbindung des Blutes als Funktion der Wasserstoffzahl," Biochemische Zeitschrift, vol. 78, pp. 112-144, 1917.

[30] A. Guzmán, L. Agüí, M. Pedrero, P. Yáñez-Sedeño, and J. M. Pingarrón, "Flow injection and HPLC determination of furosemide using pulsed amperometric detection at microelectrodes," Journal of Pharmaceutical and Biomedical Analysis, vol. 33, no. 5, pp. 923-933, 2003.

[31] N. Sultana, S. Shamim, M. A. S. Gul, and M. S. Arayne, "Simultaneous determination of gemifloxacin and diuretics in bulk, pharmaceutical dosage forms and human serum by RPHPLC," Quimica Nova, vol. 33, no. 7, pp. 1590-1593, 2010.

[32] N. Épshtein, "Structure of chemical compounds, methods of analysis and process control validation of HPLC techniques for pharmaceutical analysis," Pharmaceutical Chemistry Journal, vol. 38, no. 4, pp. 40-56, 2004.

[33] "Validation od analytical procedures: text and methodology", in International Conference on Harmonization, of Thechnical Requirements for Registration of Pharmaceuticals for Human Use, Topic Q2 (R1), Geneva, Switzerland, 2005. 
[34] T. Galaon, S. Udrescu, I. Sora, V. David, and A. Medvedovici, "High-throughput liquid-chromatography method with fluorescence detection for reciprocal determination of furosemide or norfloxacin in human plasma," Biomedical Chromatography, vol. 21, no. 1, pp. 40-47, 2007.

[35] C. D. Mills, C. Whitworth, L. P. Rybak, and C. M. Henley, "Quantification of furosemide from serum and tissues using high-performance liquid chromatography," Journal of Chromatography B, vol. 701, no. 1, pp. 65-70, 1997.

[36] S. Chawla, S. Ghosh, V. Sihorkar, R. Nellore, T. R. S. Kumar, and N. R. Srinivas, "High-perfomance liqiud chromatography method development and validation for simultaneous determination of five model compounds, antipyrine metoprolol, ketoprofen, furosemide and phenol red, as a tool for standardization of rat in situ intestinal permeability studies using timed wavelength detection," Biomedical Chromatography, vol. 20, no. 4, pp. 349-357, 2006.

[37] J. J. Pesek and M. T. Matyska, "How to retain polar and nonpolar compounds on the same HPLC stationary phase with an isocratic mobile phase," LC-GC North America, vol. 2, no. 9, pp. 1-4, 2006.

[38] S. Bankey, G. Tapadiya, J. Lamale, D. Jain, S. Saboo, and S. S. Khadabadi, "RP-HPLC method development and its validation for quantitative determination of rimonabant in human plasma," Journal of Analytical Methods in Chemistry, vol. 2012, Article ID 625979, 4 pages, 2012.

[39] D. Zendelovska and T. Stafilov, "Sample preparation and RPHPLC determination of diuretics in human body fluids," Acta Pharmaceutica, vol. 56, no. 2, pp. 115-142, 2006. 

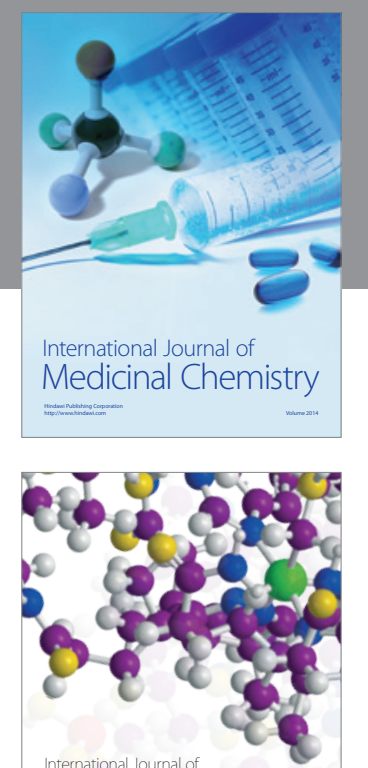

\section{Carbohydrate} Chemistry

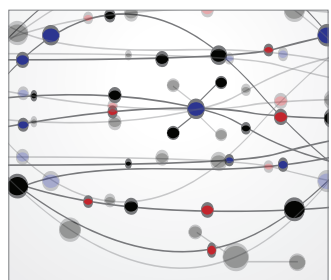

The Scientific World Journal
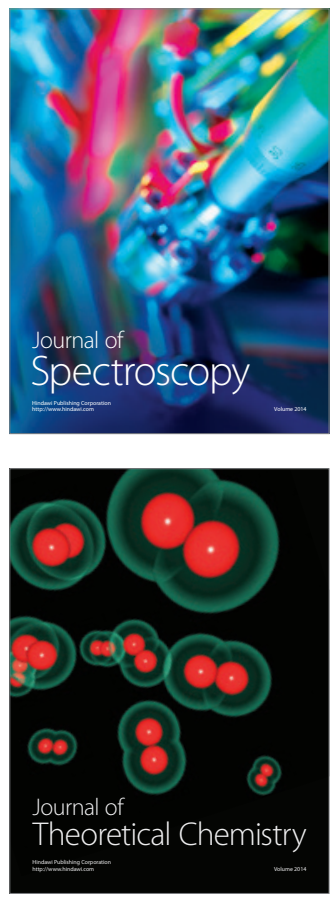
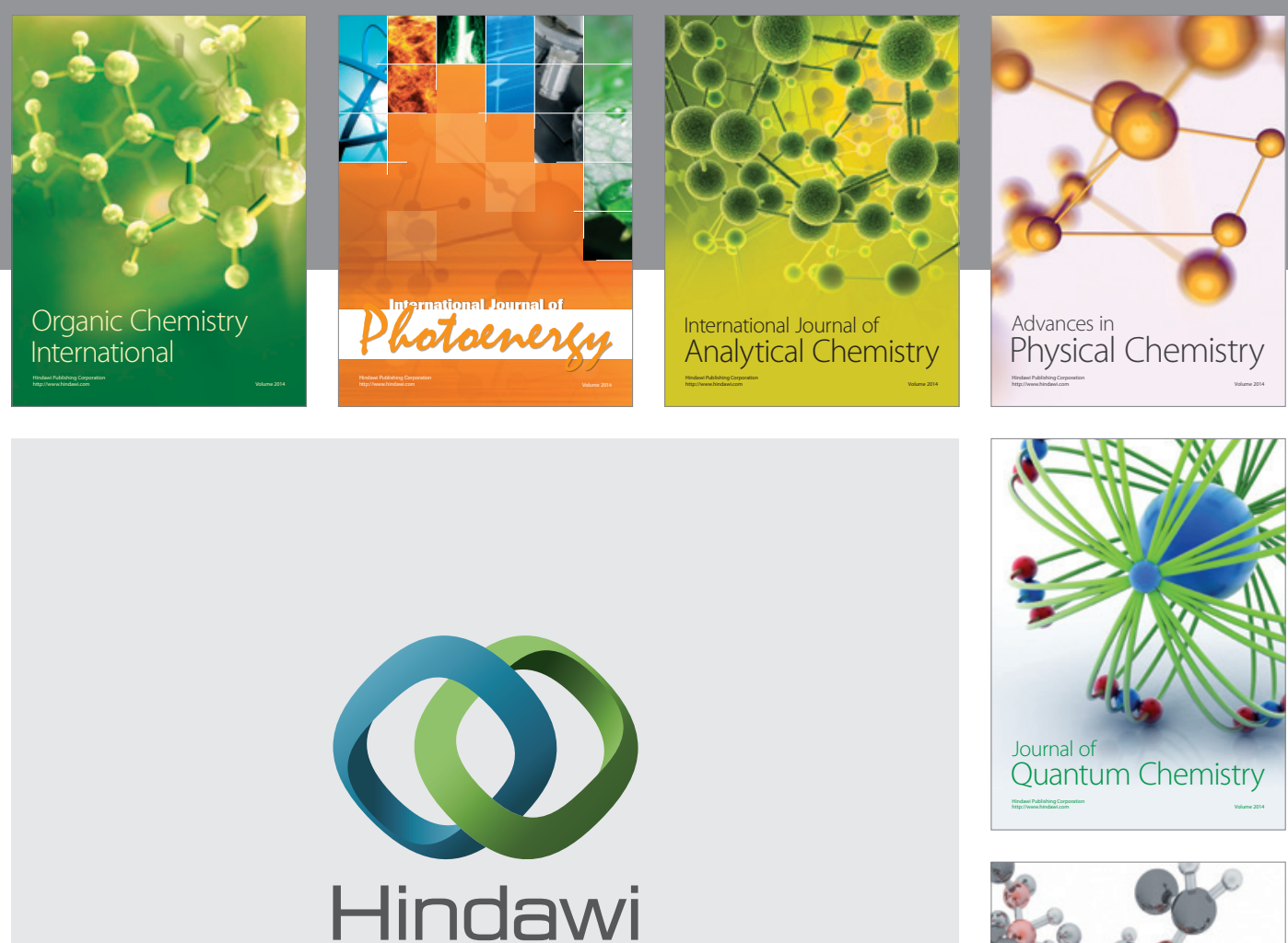

Submit your manuscripts at

http://www.hindawi.com

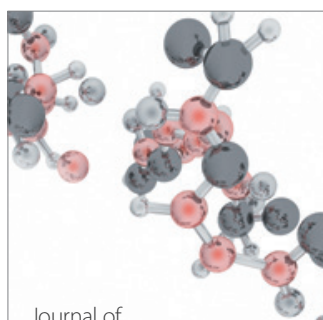

Analytical Methods

in Chemistry

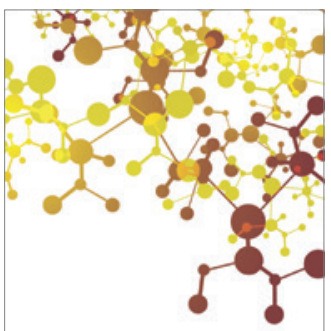

Journal of

Applied Chemistry

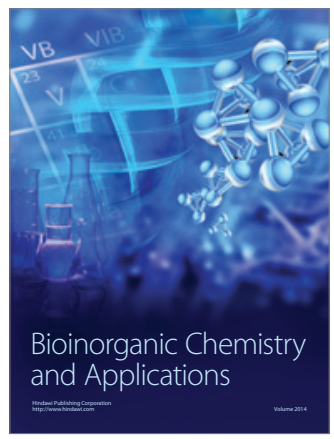

Inorganic Chemistry
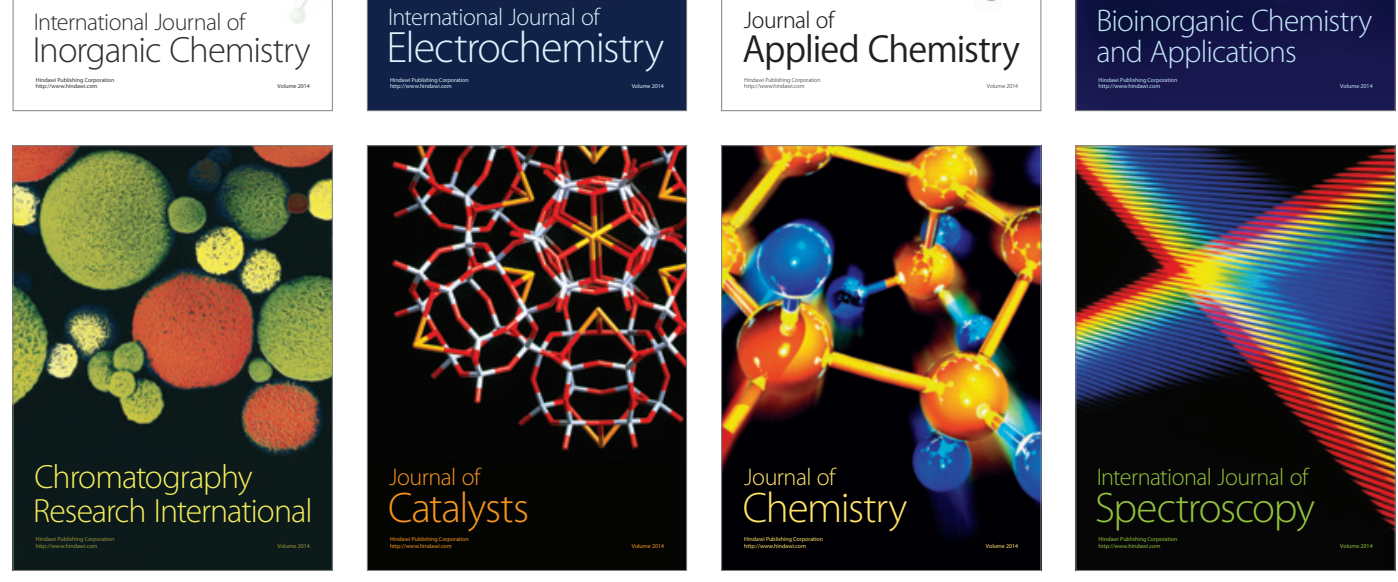